1 Chen CJ, Fang W, Chen CM, Wan YL. Spontaneous spina epidural haematomas with repeated remission and relapse.

2 Rothfus WE, Chedid MK, Deeb ZL, Abla AA, Maroon JC, Sherman RL. MR imaging in the diagnosis of spontaneous epidural haematomas. F Comput Asst Tomogr 1987;11:851-4

3 Larsson EM, Holtås S, Cronqvist S. Emergency magnetic resonance examination of patients with spinal cord symptoms. Acta Radiol 1988;26:69-75.

4 Groen RJM, Ponssen H. The spontaneous spinal epidural haematoma: a study of the aetiology. F Neurol Sci 1990;98:121-38.

5 Peltola J, Sumelhati M-L, Kumpulainen T, Dastidar P, Helén P. Spinal epidural haematoma complicating diagnostic lumbar puncture. Lancet 1996;347:131.
6 Foo D, Rosier AB. Preoperative neurological status in predicting surgical outcome of spinal epidural haematomas. Surg Neurol 1981;15:389-401.

7 Boukobza M, Guichard JP, Boissonet M, et al. Spina epidural haematoma: report of 11 cases and review of the literature Neuroradiology 1994:36:456-9.

8 McQuarrie IG. Recovery from paraplegia caused by spontaneous spinal epidural haematoma. Neurology 1978;28:224-

9 Anderson TJ, Donaldson IMacG. Spontaneous resolution of cervical spinal epidural haematoma. Postgrad Med $\mathcal{F} 1989$ 65:488-90.

\title{
Epidural lipomatosis
}

A 51-year-old man presented with radicularlike pain in the left lower limb and intermittent claudication lasting for 1 year. Pain in the legs was evoked by standing or walking more than 300 meters and rapidly relieved by sitting. Clinical examination only disclosed significant overweight (weight $100 \mathrm{~kg}$; height $163 \mathrm{~cm}$; BMI: $\left.37.6 \mathrm{~kg} / \mathrm{m}^{2}\right)$. Electromyography showed chronic neurogenic abnormalities in the muscles supplied by the left L5 nerve root. Magnetic resonance imaging (MRI) of the lumbar spine disclosed cauda equina compression by epidural lipomatosis (see figure on opposite page, A and B).

After 3 months on a hypocaloric diet leading to $20 \mathrm{~kg}$ weight loss, pain and claudication had completely resolved. MRI showed a dramatic regression of the epidural lipomatosis (figure, $\mathrm{C}$ and $\mathrm{D}$ ). In the differential diagnosis of lumbar stenosis, the clinician must keep in mind the possibility of epidural lipomatosis, even in patients without systemic glucocorticoid therapy or Cushing's disease.

YVES BOUTSEN

Department of Rheumatology

JULIAN DONCKIER

Department of Internal Medicine and Endocrinology UCL (Université Catholique de Louvain), University Hospital of Mont-Godinne, 5530 Yvoir, Belgium

Keywords: epidural lipomatosis

Submitted 3 February 1999 Accepted 12 July 1999 

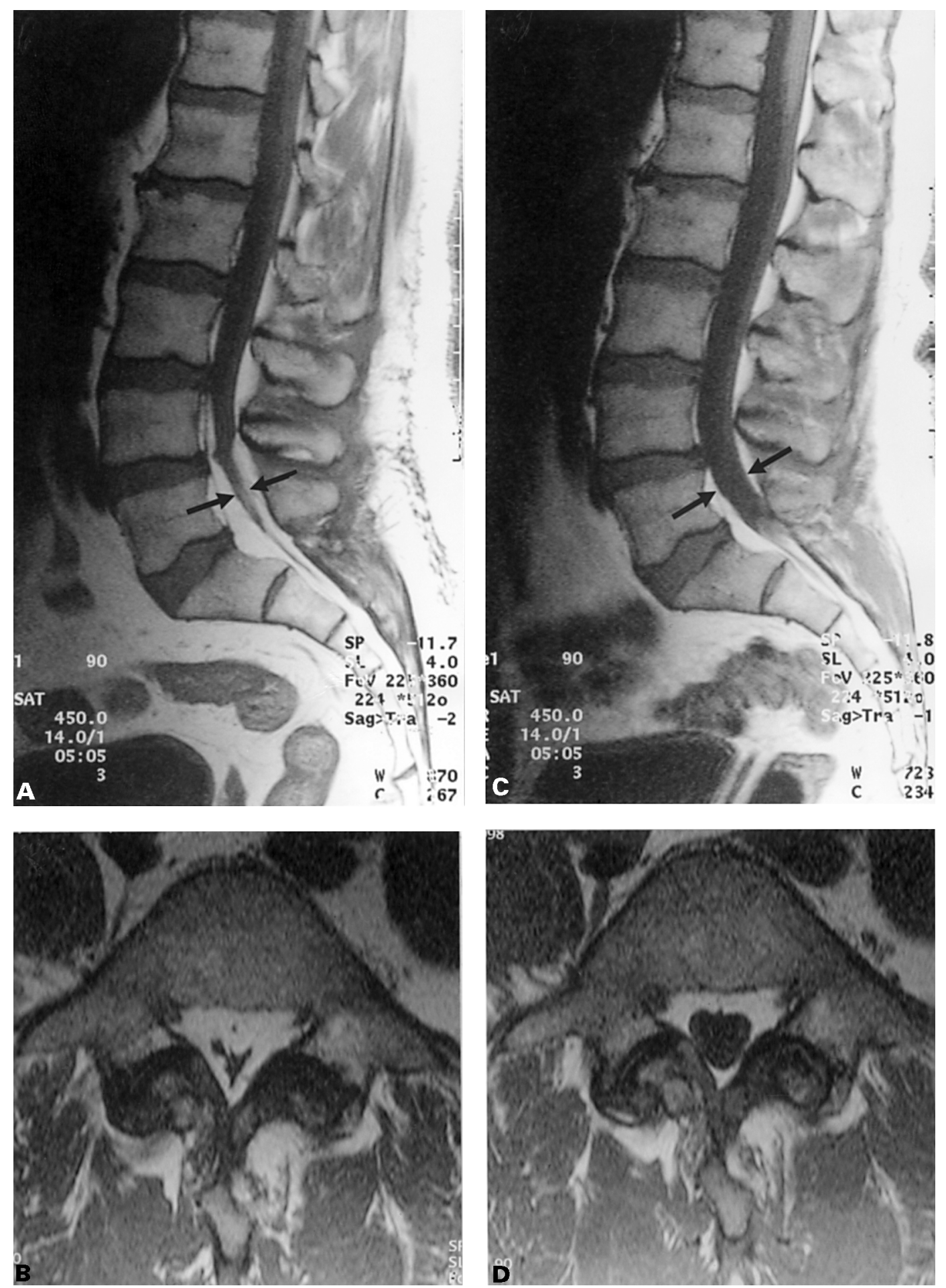

Figure Sagittal (A, C) and axial (B, D) T1-weighted MRI showing epidural fat-induced compression of the thecal sac before hypocaloric diet $(A, B)$ and normal apprearance after weight loss $(C, D)$ 